breastfed (aOR 1.41, 0.99-2.00) or partially breastfed $<4$ months (aOR 1.25, 1.06-1.47). Gastroenteritis was associated with no breastfeeding (aOR 1.77, 1.42-2.21), partial breastfeeding $<4$ months (aOR 1.90, 1.72-2.09) or 4-6 months (aOR $1.33,1.22-1.45)$. From 6 to 18 months the risk of hospitalisation for infection was higher for those who stopped any breastfeeding $<4$ months (aOR 1.40, 1.25-1.57), 4-6 (aOR 1.29, $1.13-1.49$ ) and for 6-8 months (aOR 1.11, 1.00-1.24), whereas similar risk was observed for breastfeeding 9-11 compared to breastfeeding $\geq 12$ months.

Conclusions Full breastfeeding for 6 months was associated with a reduction in hospitalisation for infections compared with absent or partial breastfeeding from $<4$ months, but not compared to full breastfeeding for 4 months. Reduced risk of hospitalisation was found with any breastfeeding up to 9 months' age but not beyond.

\section{0-087 ROLE OF ZINC IN CATCH-UP GROWTH OF LOW-BIRTH WEIGHT NEONATES}

${ }^{1} \mathrm{NE}$ Hassan, ${ }^{2} \mathrm{MA}$ Abdel-Wahed, ${ }^{2} \mathrm{OG}$ Badr Eldin, ${ }^{3}$ ER Abdel-Hamid. ${ }^{1}$ Biological Anthropology, National Research Centre, Giza, Egypt; ${ }^{2}$ Pediatrics, Ain Shams University Cairo Egypt, Cairo, Egypt; ${ }^{3}$ Child Health, National Research Centre, Giza, Egypt

\subsection{6/archdischild-2014-307384.155}

Low-birth-weight is a challenging public health problem.

Aim To clarify role of zinc on enhancing fasting catch-up growth of Low-birth-weight and find out a proposed relationship between zinc effect on growth and the main growth hormone mediator, IGF-1.

Methods Study is a double-blind-randomised-placebo-controlled trial conducted on Low-birth-weight-neonates delivered at Ain Shams University Maternity Hospital. It comprised 200 Lowbirth-weight-neonates selected from those admitted to NICU. Neonates were randomly allocated into one of the following two groups: group I: Low-birth-weight; AGA or SGA on oral zinc therapy at dose of $10 \mathrm{mg} /$ day; group II: Low-birth-weight; AGA or SGA on placebo at $10 \mathrm{mg} /$ day placebo. Anthropometric measurements were taken including birth weight, length; head, waist, chest, mid-upper arm circumferences, triceps and sub-scapular skin-fold thicknesses.

Results At 12-month-old follow-up visit, mean weight, Length; head (HC), waist, chest, mid-upper arm circumferences and triceps; also, infant's proportions had values $\geq 10$ th $\%$ for weight, length and $\mathrm{HC}$ were significantly higher among infants of group I when compared to those of group II. Oral zinc therapy was associated with $24.88 \%, 25.98 \%$ and $19.6 \%$ higher proportion of values $\geq 10$ th $\%$ regarding weight, length and $\mathrm{HC}$ at 12-month-old visit, respectively [NNT $=4,4$ and 5, respectively]. Median IGF-1 levels measured at 6 months were significantly higher in group I compared to group II [median (range): 90 (19-130) ng/ml vs. 74 $(21-130) \mathrm{ng} / \mathrm{ml})$, respectively, $\mathrm{p}=0.023]$.

Conclusion Oral zinc therapy in low-birth-weight neonates was associated with significantly more catch-up growth at 12-monthsold and significantly higher serum IGF-1 at 6-month-old.

\section{0-088 HYPERALIMENTATION AND ELECTROLYTE REQUIREMENTS IN VERY PRETERM INFANTS: THE RANDOMISED CONTROLLED SCAMP NUTRITION STUDY}

J Green, P McGowan, C Morgan. Neonatology, Liverpool Women's Hospital, Liverpool, UK

10.1136/archdischild-2014-307384.156
Background We have shown that hyperalimentation using the Standardised, Concentrated with Added Macronutrients Parenteral (SCAMP) nutrition regimen improves early preterm head growth (ISRCTN 76597892). Early hyperalimentation has been associated with potassium/phosphate deficits. SCAMP uses standardised supplementary electrolyte infusions to immediately correct deficits. We hypothesised that SCAMP (30\% more protein/ energy) would require more potassium/phosphate supplementation $\left(\mathrm{K}_{\text {supp }} / \mathrm{P}_{\text {supp }}\right)$ than a control regimen with the same electrolyte content.

Methods Control parenteral nutrition (PN) was started within 6 $\mathrm{h}$ of birth and infants $(<1200 \mathrm{~g} ;<29$ weeks) were randomised to start SCAMP or remain on control PN. Actual daily nutritional/ electrolyte intake and plasma electrolyte data (secondary outcomes) were collected for day 1-14.

Results Infants were randomised $\left(\mathrm{d}^{2}-5\right)$ to SCAMP $(\mathrm{n}=74)$ and control $(n=76)$ groups. Maximum differences in protein/ energy intakes were achieved day 5-8. These were associated with increased $\mathrm{K}_{\text {supp }} / \mathrm{P}_{\text {supp }}$ requirements in SCAMP infants (Table 1). Despite higher mean potassium/phosphate intakes in SCAMP infants (d5-8), mean (sd) plasma levels $(\mathrm{mmol} / \mathrm{l})$ were lower (not significant): potassium: 4.38 (0.81) versus 4.53 (0.81); phosphate: $1.55(0.21)$ versus $1.62(0.29)$. Additional calcium/magnesium supplementation $\left(\mathrm{Ca}_{\text {supp }} / \mathrm{Mg}_{\text {supp }}\right)$ was minimal and there was no difference between the groups.

\begin{tabular}{|c|c|c|c|c|c|c|}
\hline Difference in & d1-2 & $d^{3}-4$ & $d 5-6$ & d7-8 & d9-10 & d11-12 \\
\hline Protein $(\mathrm{g} / \mathrm{kg} / \mathrm{d})$ & 0.07 & $0.19^{* *}$ & $0.77^{* *}$ & $0.79^{* *}$ & $0.63^{* *}$ & $0.62^{* *}$ \\
\hline Energy (kcal/kg/d) & 2 & $4^{* *}$ & $10^{* *}$ & $14^{* *}$ & $14^{* *}$ & $14^{* *}$ \\
\hline $\mathrm{K}_{\text {supp }}$ (Nol) & -1 & 4 & $14^{* *}$ & 7 & 3 & 3 \\
\hline$P_{\text {supp }}(\mathrm{Nol})$ & -1 & 3 & $14^{* *}$ & $23^{* *}$ & $11^{* *}$ & -2 \\
\hline $\mathrm{Ca}_{\text {supp }}(\mathrm{Nol})$ & -2 & 1 & 2 & 2 & 0 & 1 \\
\hline $\mathrm{Mg}_{\text {supp }}(\mathrm{Nol})$ & 0 & 0 & 3 & 3 & 0 & 1 \\
\hline
\end{tabular}

Conclusion Hyperalimentation using the SCAMP regimen resulted in increased potassium/phosphate requirements.

\section{Paediatric Cancer}

\section{0-089 MICRORNAS AND CHEMORESISTANCE IN NEUROBLASTOMA}

T Flægstad, S Roth, S Bhavsar, C Løkke, P Utnes. Pediatrics, Institute of Clinical Medicine, Tromsø, Norway

\subsection{6/archdischild-2014-307384.157}

Background Neuroblastoma is a neoplasm of the sympathetic nervous system representing the most frequently diagnosed solid tumour in infants. Despite continued improvements in cancer treatment, the overall survival of patients with high risk neuroblastoma is still only $40-50 \%$. Irrespective of risk factors, neuroblastomas generally respond well to initial therapy. However, the majority of high risk patients relapse with tumours refractory to standard chemotherapeutic agents. Therefore, the understanding of biological and molecular aspects of drug resistance in 